\title{
Author Index Volume 29 (2011)
}

The issue number is given in front of the pagination

Abo, M., see Kakuda, W. (4) 365-371

Adler, R.A., see Dolbow, D.R. (3) 261-269

Ahn, S.H., see Jung, Y.J. (1) 53-59

Akbari, S., H. Ashayeri, M.A. Fahimi, M. Kamali and P.D. Lyden, The correlation of independency in activities of daily living performance with cognitive status and the intensity of neurological impairment in right-handed stroke patients (3) 311316

AlAbdulwahab, S.S., Electrical stimulation improves gait in children with spastic diplegic cerebral palsy (1) $37-43$

Alberola, M.A., see Pascual, M.G. (4) 353-357

Alcácer, V.S., see Pascual, M.G. (4) 353-357

Alemdaroglu, E., see Celik, C. (3) 229-232

Álvarez-González, L., see Rodríguez-Mutuberría, L. (4) 381-391

Arango-Lasprilla, J.C., J.M. Ketchum, A. Starkweather, E. Nicholls and A.R. Wilk, Factors predicting depression among persons with spinal cord injury 1 to 5 years post injury (1) 9-21

Arango-Lasprilla, J.C., see Gary, K.W. (3) 275-293

Ashayeri, H., see Akbari, S. (3) 311-316

Bai, D.S., see Kim, H.S. (1) 111-116

Bakheit, A.M.O., K. Fletcher and A. Brennan, Successful treatment of severe abulia with co-beneldopa (4) 347-351

Bakhshipour, A., see MahmoudAliloo, M. (4) 373-379 Balaban, C.D., see Hoffer, M.E. (2) 125

Bang, H.S., see Lee, D.R. (1) 23-27

Bender-del Busto, J.E., see Rodríguez-Mutuberría, L. (4) 381-391

Bergado, J.A., see Rodríguez-Mutuberría, L. (4) 381391

Bernabeu, M., see Laxe, S. (1) 99-110

Brennan, A., see Bakheit, A.M.O. (4) 347-351

Bryant, M.S., D.H. Rintala, J.G. Hou, E.C. Lai and E.J. Protas, Effects of levodopa on forward and backward gait patterns in persons with Parkinson's disease (3) 247-252
Byun, W.M., see Kwak, S.Y. (1) 85-90

Byun, W.M., see Kwon, H.G. (3) 271-274

Castle, P.C., see Folland, J.P. (4) 405-411

Celik, C., H. Ucan, E. Alemdaroglu and F. Oktay, Critical illness polyneuropathy: A case report (3) 229232

Cha, H.J., see Lee, D.R. (1) 23-27

Chang, C.H., see Kwak, S.Y. (1) 85-90

Chang, C.H., see Kwon, H.G. (3) 243-246

Chang, M.C., see Kim, S.H. (3) 305-310

Cho, S.-R., see Kim, S.J. (3) 233-241

Cho, Y.W., see Kim, S.H. (3) 305-310

Cho, Y.W., see Kwak, S.Y. (1) 85-90

Choi, B.Y., see Kwak, S.Y. (1) 85-90

Choi, B.Y., see Kwon, H.G. (3) 243-246

Cohen, H.S., Assessment of functional outcomes in patients with vestibular disorders after rehabilitation (2) 173-178

Cohen-Holzer, M., M. Katz-Leurer, R. Reinstein, H. Rotem and S. Meyer, The effect of combining daily restraint with bimanual intensive therapy in children with hemiparetic cerebral palsy: A selfcontrol study (1) 29-36

Costa, L., see Vidal, X. (4) 413-419

Daniels, J.A., see Dolbow, D.R. (3) 261-269

DeLuca, J. and U. Nocentini, Neuropsychological, medical and rehabilitative management of persons with multiple sclerosis (3) 197-219

DeMott, E., see Parente, R. (2) 117-124

Dolbow, D., see Gorgey, A.S. (1) 79-83

Dolbow, D.R., A.S. Gorgey, J.A. Daniels, R.A. Adler, J.R. Moore and D.R. Gater, Jr., The effects of spinal cord injury and exercise on bone mass: A literature review (3) 261-269

Fahimi, M.A., see Akbari, S. (3) 311-316

Fernández-Martínez, E., see Rodríguez-Mutuberría, L. (4) 381-391 
Fletcher, K., see Bakheit, A.M.O. (4) 347-351

Folland, J.P., B. Haas and P.C. Castle, Strength and activation of the knee musculature in Parkinson's disease: Effect of medication (4) 405-411

Fukuda, A., see Kakuda, W. (4) 365-371

Gary, K.W., E. Nicholls, A. Shamburger, L.F. Stevens and J.C. Arango-Lasprilla, Do racial and ethnic minority patients fare worse after SCI?: A critical review of the literature (3) 275-293

Gater, D.R., see Gorgey, A.S. (1) 79-83

Gater, Jr. D.R., see Dolbow, D.R. (3) 261-269

Goebel, J.A., see Slattery, E.L. (2) 143-151

Gorgey, A.S., H. Poarch, C. Harnish, J.M. Miller, D. Dolbow and D.R. Gater, Acute effects of locomotor training on neuromuscular and metabolic profile after incomplete spinal cord injury (1) 79-83

Gorgey, A.S., see Dolbow, D.R. (3) 261-269

Gottshall, K., Vestibular rehabilitation after mild traumatic brain injury with vestibular pathology (2) $167-171$

Grishin, A.A., see Solopova, I.A. (1) 67-77

Guilliams, M.E., see Wood, S.J. (2) 185-195

Haas, B., see Folland, J.P. (4) 405-411

Hain, T.C., Neurophysiology of vestibular rehabilitation (2) 127-141

Harnish, C., see Gorgey, A.S. (1) 79-83

Hashemi, T., see MahmoudAliloo, M. (4) 373-379

Hassan-Zadeh, R., see MahmoudAliloo, M. (4) 373379

Hoffer, M.E. and C.D. Balaban, Guest Editorial (2) 125

Hong, J.H., see Jung, Y.J. (1) 53-59

Hong, J.H., see Kim, H.S. (1) 111-116

Hou, J.G., see Bryant, M.S. (3) 247-252

Hulstijn, W., see van Tilborg, I.A.D.A. (3) 295-304

Ivanenko, Y.P., see Solopova, I.A. (1) 67-77

Iverson, G.L., see Silverberg, N.D. (4) 317-329

Jang, S.H., Diffusion tensor imaging studies on corticospinal tract injury following traumatic brain injury: A review (4) 339-345

Jang, S.H., see Jung, Y.J. (1) 53-59

Jang, S.H., see Kim, H.S. (1) 111-116

Jang, S.H., see Kim, S.H. (3) 305-310

Jang, S.H., see Kwak, S.Y. (1) 85-90

Jang, S.H., see Kwon, H.G. (3) 243-246

Jang, S.H., see Kwon, H.G. (3) 271-274

Jang, S.H., see Kwon, H.G. (4) 401-404

Jang, S.H., see Lee, M.Y. (4) 359-364
Jennings, P., see Parente, R. (2) 117-124

Jeong, J.Y., see Kim, H.S. (1) 111-116

Johnson, C., see Parente, R. (2) 117-124

Jung, Y.J., J.H. Hong, H.G. Kwon, J.-C. Song, C. Kim, S. Park, Y.K. Kim, S.H. Ahn and S.H. Jang, The effect of a stretching device on hand spasticity in chronic hemiparetic stroke patients (1) 53-59

Kakuda, W., M. Abo, K. Kobayashi, R. Momosaki, A. Yokoi, A. Fukuda and T. Umemori, Application of combined 6-Hz primed low-frequency rTMS and intensive occupational therapy for upper limb hemiparesis after stroke (4) 365-371

Kamali, M., see Akbari, S. (3) 311-316

Karabudak, R., see Keser, I. (1) 91-98

Karahan, A.Y., see Sahin, N. (1) 61-66

Karlberg, M., see Magnusson, M. (2) 153-156

Katz-Leurer, M., H. Rotem, O. Keren and S. Meyer, The effect of variable gait modes on walking parameters among children post severe traumatic brain injury and typically developed controls (1) 45-51

Katz-Leurer, M., see Cohen-Holzer, M. (1) 29-36

Keren, O., see Katz-Leurer, M. (1) 45-51

Keser, I., A. Meric, N. Kirdi, A. Kurne and R. Karabudak, Comparing routine neurorehabilitation programme with callisthenic exercises in multiple sclerosis (1) 91-98

Kessels, R.P.C., see van Tilborg, I.A.D.A. (3) 295-304

Ketchum, J.M., see Arango-Lasprilla, J.C. (1) 9-21

Kim, C., see Jung, Y.J. (1) 53-59

Kim, H.S., J.W. Park, D.S. Bai, J.Y. Jeong, J.H. Hong, S.M. Son and S.H. Jang, Diffusion tensor imaging findings in neurologically asymptomatic patients with end stage renal disease (1) 111-116

Kim, K.J., see Kim, S.J. (3) 233-241

Kim, O.L., see Kwon, H.G. (3) 271-274

Kim, S.H., D.G. Lee, H. You, S.M. Son, Y.W. Cho, M.C. Chang, J. Lee and S.H. Jang, The clinical application of the arcuate fasciculus for stroke patients with aphasia: A diffusion tensor tractography study (3) 305-310

Kim, S.H., see Kwak, S.Y. (1) 85-90

Kim, S.H., see Kwon, H.G. (3) 243-246

Kim, S.H., see Kwon, H.G. (3) 271-274

Kim, S.J., E.E. Kwak, E.S. Park, D.S. Lee, K.J. Kim, J.E. Song and S.-R. Cho, Changes in gait patterns with rhythmic auditory stimulation in adults with cerebral palsy (3) 233-241

Kim, Y.K., see Jung, Y.J. (1) 53-59

Kirdi, N., see Keser, I. (1) 91-98 
Kobayashi, K., see Kakuda, W. (4) 365-371

Kumar, R., see Sabut, S.K. (4) 393-400

Kurne, A., see Keser, I. (1) 91-98

Kwak, E.E., see Kim, S.J. (3) 233-241

Kwak, S.Y., S.M. Son, B.Y. Choi, C.H. Chang, W.M. Byun, S.H. Kim, Y.W. Cho and S.H. Jang, Prognostic factors for motor outcome in patients with compressed corticospinal tract by intracerebral hematoma (1) 85-90

Kwon, H.G. and S.H. Jang, Excellent recovery of aphasia in a patient with complete injury of the arcuate fasciculus in the dominant hemisphere (4) 401-404

Kwon, H.G., D.G. Lee, B.Y. Choi, C.H. Chang, S.H. Kim and S.H. Jang, Recovery of the corticospinal tract after injury by transtentorial herniation: A case report (3) 243-246

Kwon, H.G., O.L. Kim, S.H. Kim, D.G. Lee, W.M. Byun and S.H. Jang, Cortical reorganization of hand motor function to face somatotopy in a patient with brain injury: A functional MRI study (3) 271-274

Kwon, H.G., see Jung, Y.J. (1) 53-59

Kwon, Y.-H. and J.-W. Park, Different cortical activation patterns during voluntary eccentric and concentric muscle contractions: An fMRI study (3) 253-259

Lai, E.C., see Bryant, M.S. (3) 247-252

Laxe, S., N. Zasler, U. Tschiesner, R. López-Blazquez, J.M. Tormos and M. Bernabeu, ICF use to identify common problems on a TBI neurorehabilitation unit in Spain (1) 99-110

Lee, D.G., see Kim, S.H. (3) 305-310

Lee, D.G., see Kwon, H.G. (3) 243-246

Lee, D.G., see Kwon, H.G. (3) 271-274

Lee, D.R., N.G. Lee, H.J. Cha, Y.S. O, S.H. You, J.H. Oh and H.S. Bang, The effect of robo-horseback riding therapy on spinal alignment and associated muscle size in MRI for a child with neuromuscular scoliosis: An experimenter-blind study (1) 23-27

Lee, D.S., see Kim, S.J. (3) 233-241

Lee, J., see Kim, S.H. (3) 305-310

Lee, M.Y. and S.H. Jang, Ipsilateral motor cortex activation by unaffected hand movements in patients with cerebral infarct (4) 359-364

Lee, N.G., see Lee, D.R. (1) 23-27

Loehr, J.A., see Wood, S.J. (2) 185-195

López, M., see Rodríguez-Mutuberría, L. (4) 381-391

López-Blazquez, R., see Laxe, S. (1) 99-110

Lyden, P.D., see Akbari, S. (3) 311-316
Magnusson, M., M. Karlberg and F. Tjernström, 'PREHAB': Vestibular prehabilitation to ameliorate the effect of a sudden vestibular loss (2) 153-156

Mahadevappa, M., see Sabut, S.K. (4) 393-400

MahmoudAliloo, M., A. Bakhshipour, T. Hashemi, A.R. Roofigari and R. Hassan-Zadeh, The correlation of cognitive capacity with recovery of hand sensibility after peripheral nerve injury of upper extremity (4) 373-379

Martínez-Segón, S., see Rodríguez-Mutuberría, L. (4) 381-391

Meric, A., see Keser, I. (1) 91-98

Meyer, S., see Cohen-Holzer, M. (1) 29-36

Meyer, S., see Katz-Leurer, M. (1) 45-51

Miller, J.M., see Gorgey, A.S. (1) 79-83

Mogensen, J., see Wilms, I. (3) 221-227

Momosaki, R., see Kakuda, W. (4) 365-371

Moore, J.R., see Dolbow, D.R. (3) 261-269

Morral, A., see Vidal, X. (4) 413-419

Nicholls, E., see Arango-Lasprilla, J.C. (1) 9-21

Nicholls, E., see Gary, K.W. (3) 275-293

Nocentini, U., see DeLuca, J. (3) 197-219

O, Y.S., see Lee, D.R. (1) 23-27

Oh, J.H., see Lee, D.R. (1) 23-27

Oktay, F., see Celik, C. (3) 229-232

Osipowicz, K.Z., see Tracy, J.I. (4) 331-338

Parente, R., E. DeMott, C. Johnson, P. Jennings and R. Silver, Measuring and manipulating subjective organization after traumatic brain injury (2) 117124

Park, E.S., see Kim, S.J. (3) 233-241

Park, J.W., see Kim, H.S. (1) 111-116

Park, J.-W., see Kwon, Y.-H. (3) 253-259

Park, S., see Jung, Y.J. (1) 53-59

Pascual, M.G., V.S. Alcácer, M.V.P. Pomares and M.A. Alberola, Brown-Séquard-plus syndrome after a stab injury (4) 353-357

Poarch, H., see Gorgey, A.S. (1) 79-83

Pomares, M.V.P., see Pascual, M.G. (4) 353-357

Protas, E.J., see Bryant, M.S. (3) 247-252

Reinstein, R., see Cohen-Holzer, M. (1) 29-36

Rintala, D.H., see Bryant, M.S. (3) 247-252

Rodríguez-Mutuberría, L., L. Álvarez-González, M. López, J.E. Bender-del Busto, E. FernándezMartínez, S. Martínez-Segón and J.A. Bergado, Efficacy and tolerance of a Neurological Restoration Program in stroke patients (4) 381-391 
Roofigari, A.R., see MahmoudAliloo, M. (4) 373-379

Rotem, H., see Cohen-Holzer, M. (1) 29-36

Rotem, H., see Katz-Leurer, M. (1) 45-51

Sabut, S.K., C. Sikdar, R. Kumar and M. Mahadevappa, Functional electrical stimulation of dorsiflexor muscle: Effects on dorsiflexor strength, plantarflexor spasticity, and motor recovery in stroke patients (4) 393-400

Sahin, N., H. Ugurlu and A.Y. Karahan, Efficacy of therapeutic ultrasound in the treatment of spasticity: A randomized controlled study (1) 61-66

Shamburger, A., see Gary, K.W. (3) 275-293

Sikdar, C., see Sabut, S.K. (4) 393-400

Silver, R., see Parente, R. (2) 117-124

Silverberg, N.D. and G.L. Iverson, Etiology of the postconcussion syndrome: Physiogenesis and psychogenesis revisited (4) 317-329

Sinks, B.C., see Slattery, E.L. (2) 143-151

Slattery, E.L., B.C. Sinks and J.A. Goebel, Vestibular tests for rehabilitation: Applications and interpretation (2) 143-151

Solopova, I.A., D.Y. Tihonova, A.A. Grishin and Y.P. Ivanenko, Assisted leg displacements and progressive loading by a tilt table combined with FES promote gait recovery in acute stroke (1) 67-77

Son, S.M., see Kim, H.S. (1) 111-116

Son, S.M., see Kim, S.H. (3) 305-310

Son, S.M., see Kwak, S.Y. (1) 85-90

Song, J.-C., see Jung, Y.J. (1) 53-59

Song, J.E., see Kim, S.J. (3) 233-241

Sparto, P.J., see Whitney, S.L. (2) 157-166

Staab, J.P., Behavioral aspects of vestibular rehabilitation (1) 179-183

Starkweather, A., see Arango-Lasprilla, J.C. (1) 9-21

Stevens, L.F., see Gary, K.W. (3) 275-293

Tihonova, D.Y., see Solopova, I.A. (1) 67-77

Tjernström, F., see Magnusson, M. (2) 153-156
Tormos, J.M., see Laxe, S. (1) 99-110

Tracy, J.I. and K.Z. Osipowicz, A conceptual framework for interpreting neuroimaging studies of brain neuroplasticity and cognitive recovery (4) $331-338$

Tschiesner, U., see Laxe, S. (1) 99-110

Tur, M., see Vidal, X. (4) 413-419

Ucan, H., see Celik, C. (3) 229-232

Ugurlu, H., see Sahin, N. (1) 61-66

Umemori, T., see Kakuda, W. (4) 365-371

van Tilborg, I.A.D.A., R.P.C. Kessels and W. Hulstijn, Learning by observation and guidance in patients with Alzheimer's dementia (3) 295-304

Vidal, X., A. Morral, L. Costa and M. Tur, Radial extracorporeal shock wave therapy (rESWT) in the treatment of spasticity in cerebral palsy: A randomized, placebo-controlled clinical trial (4) 413-419

West, S.L., Substance use among persons with traumatic brain injury: A review (1) 1-8

Whitney, S.L. and P.J. Sparto, Principles of vestibular physical therapy rehabilitation (2) 157-166

Wilk, A.R., see Arango-Lasprilla, J.C. (1) 9-21

Wilms, I. and J. Mogensen, Dissimilar outcomes of apparently similar procedures as a challenge to clinical neurorehabilitation and basic research: When the same is not the same (3) 221-227

Wood, S.J., J.A. Loehr and M.E. Guilliams, Sensorimotor reconditioning during and after spaceflight (2) 185-195

Yokoi, A., see Kakuda, W. (4) 365-371

You, H., see Kim, S.H. (3) 305-310

You, S.H., see Lee, D.R. (1) 23-27

Zasler, N., see Laxe, S. (1) 99-110 